\title{
Self-compassion as a Stress Moderator: A Cross-sectional Study of 1700 Doctors, Nurses, and Medical Students
}

\author{
Vinayak Dev ${ }^{1}$ - Antonio T. Fernando III $^{1} \cdot$ Nathan S. Consedine ${ }^{1}$ (I) \\ Published online: 11 February 2020 \\ (C) Springer Science+Business Media, LLC, part of Springer Nature 2020
}

\begin{abstract}
Objectives Work stress is common in healthcare and reliably predicts negative outcomes, including burnout and lower quality of life (QOL). However, few studies have investigated factors that might attenuate the impact of stress on these negative outcomes. We investigated whether the tendency to be kind to the self during times of difficulty—self-compassion — might buffer the effect of work stress on outcomes.

Methods Registered nurses $(n=801)$, physicians $(n=516)$, and medical students $(n=383)$ were recruited using convenience sampling in New Zealand. Following consent, participants $(N=1700)$ completed a survey including the Copenhagen Burnout Inventory, Satisfaction with Life Scale, and Self-Compassion Scale-Short Form.

Results Across groups, greater work stress consistently predicted greater burnout and lower QOL, while greater self-compassion predicted lower burnout and better QOL. Self-compassion moderated the relationship between stress and burnout in nurses (albeit in the opposite direction to what had been predicted), but not in doctors or medical students.

Conclusions While self-compassion predicted better outcomes (and may thus represent a target to enhance wellbeing), it strengthened the association between stress and burnout in nurses. How self-compassion impacts the experience of stress and its correlates and why it does so differently in different groups of professionals remains unclear.
\end{abstract}

Keywords Healthcare $\cdot$ Self-compassion $\cdot$ Stress $\cdot$ Burnout $\cdot$ Quality of life

Stress - broadly defined as the evaluation of a situation as exceeding coping resources (Folkman 2013) -is common in healthcare professionals (Coomber et al. 2002; Weinberg \& Creed 2000). Stress is thought to lead to a range of negative outcomes, including anxiety and depression (Weinberg \& Creed 2000), emotional exhaustion (McManus, Winder, \& Gordon 2002), strained relationships (Ramirez, Graham, Richards, Gregory, \& Cull 1996), lower work satisfaction (Coomber et al. 2002), greater burnout (Visser, Smets, Oort, $\&$ de Haes 2003), and lower quality of life (QOL; Su, Weng, Tsang, \& Wu 2009). Of the negative outcomes that stress predicts, burnout and QOL are central to professional practice. QOL is inherently important, while burnout has been linked to poorer immune functioning (Nakamura, Nagase, Yoshida, \& Ogino 1999) as well as to greater substance abuse (Coomber

Nathan S. Consedine

n.consedine@auckland.ac.nz

1 Department of Psychological Medicine, University of Auckland, Auckland, New Zealand et al. 2002), sick leave (Anagnostopoulos \& Niakas 2010), and compassion-fatigue (Sprang, Clark, \& Whitt-Woosley 2007). We focus on burnout rather than compassion fatigue in this study because of concerns about the compassion-fatigue construct (Sinclair, Raffin-Bouchal, Venturato, MijovicKondejewski, \& Smith-MacDonald 2017) and its tendency to encourage the study of clinician-centric factors rather than capacitating a systemic evaluation of the factors that may enhance or deter compassion (Fernando \& Consedine 2014).

Despite a wealth of evidence linking stress to negative outcomes in healthcare professionals, most work in this area has focused on investigating how external, work-related factors, such as unmet professional standards, inadequate availability of resources, and long and tiring working hours (Coomber et al. 2002; Dellve \& Wikström 2009; Happell et al. 2013; Isikhan, Comez, \& Zafer Danis 2004; Van Den Tooren \& De Jonge 2008; Visser, Smets, Oort, \& de Haes 2003) may moderate the links between stress and its negative consequences. While a few studies have considered resilience-type factorsmindfulness and meditation (Jackson, 1999; Shapiro, Brown, \& Biegel 2007; Stafford-Brown \& Pakenham,2012), and 
acceptance (Kalichman, Gueritault-Chalvin, \& Demi 2000; Stafford-Brown \& Pakenham 2012) - the need to identify resiliency-type factors that might 'buffer' the association between stress and its negative consequences remains (Dollard \& Winefield 1996). Furthermore, there is an ongoing need to identify resiliency-type factors that may (a) act as stressmoderators in samples of healthcare professionals (rather than in other groups), and (b) are amenable to change.

Recent studies of self-compassion - the ability or tendency to respond to the self in times of failure or distress with gentleness, kindness, and understanding (Neff 2003a, b; Neff 2016) - suggests this characteristic is malleable (e.g., Friis, Johnson, Cutfield, \& Consedine 2015) and may be of benefit. Self-compassion is a resiliency factor (Neff \& McGehee 2010) linked to a large range of psychological outcomes, including less psychopathology (MacBeth \& Gumley 2012), depression (Soysa \& Wilcomb 2015), stress (Neely, Schallert, Mohammed, Roberts, \& Chen 2009), and burnout (Alkema, Linton, \& Davies 2008), as well as greater well-being (Zessin, Dickhäuser, \& Garbade 2015). Other studies have shown that self-compassion attenuates or 'buffers' the association between negative psychological constructs and both mental (e.g., Körner et al. 2015) and physical (e.g., Friis et al. 2015) health outcomes. To this point, however, research has yet to evaluate self-compassion as a potential stress moderator in a large and diverse sample of healthcare professionals.

One recent study found that elements of self-compassion (self-kindness and common humanity) weakened the association between empathic concern and compassion-fatigue in nurses (Duarte, Pinto-Gouveia, \& Cruz 2016). However, this study did not specifically test for stress moderation, was specific to (Portuguese) nurses, and had a relatively small $(N=$ $280)$ and predominantly female (81\%) sample. Given systemic culture- and role-related differences between physicians and nurses, a nursing- and sex-based sample is an important limitation of the study.

More fully, there are important differences in the modal cultures that exist in nursing and medicine that might change the way self-compassion is viewed or experienced as well as whether it buffers stress's effects. First, in contrast to medicine, nursing has traditionally emphasized compassion, deeming it the central tenet of clinical practice (Fry et al. 2013). Conversely, while compassion forms a part of the mandated responsibilities in medicine (Wear \& Zarconi 2008), the medical tradition typically views patients' illnesses and symptoms within the biomedical paradigm (de Zulueta 2013; Mead \& Bower 2000).

Second, relative to physicians, nursing culture tends to be more collectively oriented, see institutional shortcomings as explaining variability in clinical practice, and experience protocols as enhancing autonomy (Degeling, Kennedy, \& Hill 2001). Nurses prefer working in teams (Degeling et al. 2001) and trainee nurses (more than medical trainees) endorse collective decision-making (Horsburgh, Perkins, Coyle, \& Degeling 2006). Cultural differences of this kind likely precede training (Perkins, Horsburgh, \& Coyle 2008), with particular personality types appearing differentially likely to choose particular professions (Hardigan \& Cohen 1999). Prima facie, such differences may be reflected in different levels of self-compassion across professional groups as well as variation in its links to outcomes.

Third, nurses and physicians occupy different positions in the hierarchies of healthcare and have normatively different responsibilities (Richards et al. 2002; White 2000). Given differences in caseloads, timeframes, and work-related challenges, the sources of work-related stress also likely differ (Eltarhuni 2016). Compared to doctors, nurses occupy positions with lower power (Daiski 2004) as do more recent graduates. Lower work-related autonomy may be particularly salient in ward environments (Mantzoukas \& Jasper 2004) or for more recent trainees (Law \& Chan 2015). Consequently, the sources of stress may differ between physicians and nurses as well as between more versus less-experienced workers. Professional development, experience, seniority, and ageing may lead to a greater tolerance of perceived failures, complexity, and ambiguity, and greater emotional maturity (Moltu, Binder, \& Nielsen 2010), allowing more experienced clinicians (or those with more control over stressors) to more effectively manage stress and/or recognize their lack of infallibility. Thus, although it is unknown at this point, such differences create the possibility that the links between stress and burnout may differ in different groups of workers and/or that self-compassion may have different implications at different stages of development.

The current study documents the associations between selfcompassion, stress, burnout, and QOL in a large sample of healthcare workers, testing whether self-compassion buffers the effect of stress on outcomes and evaluating whether any buffering function is comparably evident in samples of doctors, nurses, and medical students. Based on prior work, it was hypothesised that greater stress would predict greater burnout and lower QOL, that greater self-compassion would predict lower burnout and greater QOL, and that self-compassion would buffer (i.e., weaken) the association between stress and outcomes (burnout and QOL). We treat the possibility of differential moderation across groups as an exploratory question.

\section{Method}

\section{Participants}

Participants for the study included nurses, physicians, and medical students. Participants were recruited from December 2013 to July 2014, from March 2012 to July 2013, and from November 2013 to April 2016, for studies of doctors, nurses, and medical students, respectively. Recruitment employed non- 
random convenience sampling, with the three samples accessed via a lecture series conducted by one of the authors (A. F.), at medical meetings and hospital grand rounds, contacts and referrals in hospitals and clinics in New Zealand, and e-mails distributed via professional organizations (i.e., District Health Boards, Primary Health Organizations, speciality interest groups, and medical and nursing schools). Inclusion criteria required that participants were practicing as medical professionals, were registered nurses, or were enrolled as medical students in New Zealand. Prospective participants were sent an email containing a link to a description of the study and a 20-min survey.

Participants were drawn from three large scale studies of compassion in healthcare, one of physicians (Fernando \& Consedine 2017), one of nurses (Dev, Fernando, Lim, \& Consedine 2018), and one of medical students (Dev, Fernando, Kirby, \& Consedine 2019). Of the 1700 participants included in this study (Table 1), $47.10 \%$ were nurses, $30.40 \%$ were physicians, and $22.50 \%$ were medical students. Across samples, $74.20 \%$ were female. The average age of nurses was 45.46 years, physicians 43.62 years, and of medical students 24.07 years. Nurses averaged 26.11 years of clinical experience, physicians 27.02 years, and medical students 1.06 years. Participants mainly identified as New Zealanders (57.17\%), followed by British (11.57\%), Chinese (4.27\%), Indian (3.60\%), South African (2.97\%), Filipino (1.83\%), and Other (19.0\%).

\section{Procedure}

After providing informed consent, the participants completed the survey, which included questions indexing demographics, characteristics of clinical practice, attitudes, and emotions and behaviours regarding patient care. Participation in each study was voluntary and anonymous.

\section{Measures}

Background Characteristics Participants identified as 'male or female' and self-assigned to ethnic categories (see Table 1). For doctors and nurses, clinical experience was calculated by subtracting participants' self-reported year of graduation from the current year and adding 2 years (physicians and nurses begin patient contact in the final 2 years of training in New Zealand). Clinical experience was calculated for medical students by subtracting four from years at medical school, while assuming a ' 0 ' for any negative values (given six total years medical training and patient contact only in the last 2 years).

Work Stress Work stress was assessed using an aggregate of the $z$-standardized scores of three items indexing patient-load, work-load, and overall work-stress. Participants were asked, 'How would you characterize your current patient load?', 'How would you characterize your overall workload?', and 'Overall, how stressful is your work?'. Of these, responses to patient-load- and work-load- related questions were obtained using a five-point scale from 'too much' to 'too little', while responses to work-stress were obtained using a seven-point scale from 'not at all' to 'very stressful'. The responses to work-load and patient-load variables were reverse-coded before aggregation. The aggregate had adequate internal reliability in each of the samples (Cronbach's $\alpha_{T}=.75 ; \alpha_{N}=.79$; $\alpha_{P}=.73 ; \alpha_{S}=.63$ ).

Table 1 Demographic characteristics of the three professional subsamples

\begin{tabular}{|c|c|c|c|c|c|}
\hline Variable & Nurses $(n=801)$ & Physicians $(n=516)$ & Medical Students $(n=383)$ & Difference $(F)$ & Post hoc \\
\hline \multicolumn{6}{|l|}{ Ethnicity } \\
\hline New Zealander & $67.80 \%$ & $42.60 \%$ & $61.10 \%$ & & \\
\hline British & $12.90 \%$ & $20.50 \%$ & $1.30 \%$ & & \\
\hline Chinese & $1.50 \%$ & $0.60 \%$ & $10.70 \%$ & & \\
\hline Indian & $2.50 \%$ & $4.10 \%$ & $4.20 \%$ & & \\
\hline South African & $2.10 \%$ & $5.20 \%$ & $1.60 \%$ & & \\
\hline Filipino & $3.70 \%$ & $1.00 \%$ & $0.80 \%$ & & \\
\hline Other & $9.00 \%$ & $26.00 \%$ & $20.00 \%$ & & \\
\hline$\%$ Female & $93.90 \%$ & $52.70 \%$ & $62.10 \%$ & & \\
\hline Age & $45.46(11.80)$ & $43.62(11.57)$ & $24.07(3.31)$ & $587.74 * *$ & $\mathrm{~N}>\mathrm{P}>\mathrm{S}$ \\
\hline Years of clinical experience & $26.11(12.75)$ & $27.02(11.63)$ & $1.06(0.82)$ & $814.32 * *$ & $\mathrm{P}, \mathrm{N}>\mathrm{S}$ \\
\hline Stress & $0.18(0.86)$ & $-0.01(0.76)$ & $-0.36(0.68)$ & $60.91 * *$ & $\mathrm{~N}>\mathrm{P}>\mathrm{S}$ \\
\hline Burnout & $2.74(0.66)$ & $2.57(0.56)$ & $2.59(0.53)$ & $14.63 * *$ & $\mathrm{~N}>\mathrm{S}, \mathrm{P}$ \\
\hline Quality of life & $4.92(1.34)$ & $5.30(1.25)$ & $5.25(1.18)$ & $16.87 * *$ & $\mathrm{P}, \mathrm{S}>\mathrm{N}$ \\
\hline Self-compassion & $3.24(0.67)$ & $3.24(0.68)$ & $2.92(0.67)$ & $32.72 * *$ & $\mathrm{P}, \mathrm{N}>\mathrm{S}$ \\
\hline
\end{tabular}

Note. ${ }^{*} p<0.05, * * p<0.01$; 'N'= nurses, 'P' = physicians and 'S'= medical students 
Burnout Professional burnout was assessed using the widelyused Copenhagen Burnout Inventory ( $C B I$; Kristensen, Borritz, Villadsen, \& Christensen 2005). This scale captures elements of exhaustion, negative job attitudes, and a loss of concern and feeling for patients. Items are rated on a five-point rating scale from 1 ('never') to 5 ('always'), and the scale has robust psychometric properties (Kristensen et al. 2005). Internal reliability is commonly above .80 (Cronbach's $\alpha=.85-.87)$ and the measure has high face, convergent, divergent, and predictive validity (Kristensen et al. 2005; Robinson, Denny, Milfont, Merry, \& Ameratunga 2008). It had strong internal reliability in the samples used in this study (Cronbach's $\alpha_{T}=.91 ; \alpha_{N}=.92 ; \alpha_{P}=.90 ; \alpha_{S}=.89$ ).

Quality of Life QOL was assessed using the Satisfaction with Life Scale (SWLS; Diener, Emmons, Larsen, \& Griffin 1985). The SWLS is a self-report measure of perceived QOL and general life satisfaction, consisting of five items rated on a seven-point scale from 1 ('strongly disagree') to 7 ('strongly agree'). It is psychometrically robust with high internal (Cronbach's $\alpha \geq .81)$ and test-retest $(r \geq .77)$ reliability (Senol-Durak, Durak, \& Gencoz 2010), and high face, construct, discriminant, and convergent validity (Senol-Durak et al. 2010). Internal reliability for the total scores was strong for the samples in this study (Cronbach's $\alpha_{T}=.90 ; \alpha_{N}=.90$; $\left.\alpha_{P}=.90 ; \alpha_{S}=.87\right)$.

Self-compassion Self-compassion was assessed using the SelfCompassion Scale-Short Form ( $S C S-S F$; Raes, Pommier, Neff, \& Van Gucht 2011). The SCS-SF is a widely-used self-report measure of self-compassion and indexes the ability or tendency to respond to oneself with kindness and understanding in times of failure or distress. The scale has 12 items rated on a five-point scale from 1 ('almost never') to 5 ('almost always'). It has robust psychometric properties; possessing high internal (Cronbach's $\alpha \geq .80$ ) and face, content, convergent and divergent validity (Neff 2016; Raes et al. 2011). The total score had good internal reliability in the current study (Cronbach's $\alpha_{T}=.85 ; \alpha_{N}=.84 ; \alpha_{P}=.86 ; \alpha_{S}=.86$ ).

\section{Data Analyses}

Missing data were imputed using means from the original subsamples. First, Pearson's and Spearman's correlations tested the associations between predictors, confounds (age, clinical experience, and sex), and outcomes (Table 2). Greater age and experience have previously been associated with lower stress (Isikhan, Comez, \& Zafer Danis 2004), lower burnout (Dev et al. 2019), greater QOL (Wenzel et al. 1999), and greater self-compassion (Dev et al. 2018). Equally, females sometimes report greater stress (Matud 2004), greater burnout (Linzer et al. 2002), lower QOL (Michel, Bisegger, Fuhr, \& Abel 2009), and may be less self-compassionate (Neff \&
McGehee 2010). To assess possible group differences in the univariate correlations, Fisher $r$-to- $z$ transformation tests (Lowry 2018) were used (Table 2). These tests were not performed for the correlations amongst control variables.

Second, to test the primary hypotheses, two-step multiple regressions were used to examine the relationships between stress and its negative consequences (greater burnout and lower QOL) and to test for main or moderation effects associated with self-compassion. Together with control variables, $z$-standardized stress and self-compassion scores were entered in Step 1 . To test the possibility of self-compassion mitigating the association between stress and its negative consequences, the interaction between the stress and self-compassion scores was entered in Step 2. To facilitate interpretation of possible moderation, a 'simple slopes' graph (Dawson 2013) was used. To prevent possible multicollinearity, only clinical experience was included in the regressions, rather than both age and clinical experience. To preliminarily test for potential differences in the association between self-compassion and outcomes across samples, models were run separately for nurses, doctors and medical students (Tables 3 and 4).

\section{Results}

\section{Univariate Correlations}

In terms of the primary variables: in nurses, greater stress was associated with greater burnout and lower QOL; greater selfcompassion was associated with lower burnout and greater QOL. In physicians, greater stress was associated with greater burnout, lower QOL, and lower self-compassion; greater selfcompassion was associated with lower burnout and greater QOL. In medical students, greater stress was associated with greater burnout, lower QOL and lower self-compassion; greater self-compassion was associated with lower burnout and greater QOL (Table 2).

\section{Between-group Contrasts of Univariate Correlations}

In terms of the primary variables, Fisher $r$-to- $z$ transformationbased comparisons (Table 2) revealed that the association between stress and QOL was stronger in nurses than in physicians $(z=3.52, p<.001)$ or medical students $(z=3.37$, $p<.001)$. The association between stress and selfcompassion was stronger in nurses than in physicians $(z=$ $2.52, p=.006)$. The association between burnout and QOL was stronger in nurses than in medical students $(z=1.73$, $p=.042)$. The association between burnout and selfcompassion was stronger in nurses than in physicians $(z=$ 1.91, $p=.028)$. The association between self-compassion and QOL was stronger in nurses relative to physicians $(z=$ $2.27, p=.012$ ). 
Table 2 Correlations between demographics, stress, burnout, quality of life, and self-compassion

\begin{tabular}{|c|c|c|c|c|c|c|c|c|}
\hline & Sample & Age & Experience & Sex & Stress & Burnout & Quality of life & $\begin{array}{l}\text { Self- } \\
\text { compassion }\end{array}$ \\
\hline \multirow[t]{3}{*}{ Age } & Nurses & - & $.83^{* *}$ & .03 & $-.08^{*}$ & $-.23^{* *, c}$ & .02 & $.17^{* *}$ \\
\hline & Physicians & - & $.97^{* *}$ & -.08 & $-.09^{*}$ & $-.22^{* *, \mathrm{c}}$ & -.03 & $.22^{* * *}$ \\
\hline & Medical students & - & $.33^{* * *}$ & -.03 & -.06 & $-.09^{\mathrm{a}, \mathrm{b}}$ & .00 & $.14^{\text {*** }}$ \\
\hline \multirow[t]{3}{*}{ Experience } & Nurses & $.83^{* *}$ & - & .04 & $-.11^{* * *}$ & $-.22^{* *, b}$ & .05 & $.14^{* *}$ \\
\hline & Physicians & $.97^{* *}$ & - & -.08 & $-.07^{\mathrm{c}}$ & $-.22^{* *, \mathrm{~b}}$ & $-.03^{\mathrm{c}}$ & $.22^{* *}$ \\
\hline & Medical students & $.33^{* *}$ & - & -.04 & $-.18^{* *, \mathrm{~b}}$ & $-.10^{\mathrm{a}, \mathrm{b}}$ & $.10^{*}, \mathrm{~b}$ & $.15^{* *}$ \\
\hline \multirow[t]{3}{*}{${ }^{\#} \operatorname{Sex}$} & Nurses & .03 & .04 & - & $-.03^{\mathrm{b}, \mathrm{c}}$ & $.00^{\mathrm{b}}$ & $.05^{\mathrm{b}, \mathrm{c}}$ & $-.07^{*}$ \\
\hline & Physicians & -.06 & -.07 & - & $.16^{* *, a}$ & $.17^{* *, \mathrm{a}, \mathrm{c}}$ & $-.13^{* *, \mathrm{a}, \mathrm{c}}$ & $-.10^{*}$ \\
\hline & Medical students & -.04 & -.04 & - & $.10^{*, \mathrm{a}}$ & $.04^{\mathrm{b}}$ & $.17^{* * a, b}$ & $-.11^{*}$ \\
\hline \multirow[t]{3}{*}{ Stress } & Nurses & $-.08^{*}$ & $-.11^{* *}$ & -.02 & - & $.51^{* *}$ & $-.11^{* *, b, c}$ & $-.06^{\mathrm{b}}$ \\
\hline & Physicians & $-.09^{*}$ & -.07 & $.16^{* *}$ & - & $.55^{* *}$ & $-.30^{* *, \mathrm{a}}$ & $-.20^{* *, \mathrm{a}}$ \\
\hline & Medical students & -.06 & $-.18^{* *}$ & .10 & - & $.52^{* *}$ & $-.31^{* *, \mathrm{a}}$ & $-.21^{* *}$ \\
\hline \multirow[t]{3}{*}{ Burnout } & Nurses & $-.23^{* *}$ & $-.22^{* *}$ & -.01 & $.51^{* * *}$ & - & $-.36^{* *, c}$ & $-.36^{* *, b}$ \\
\hline & Physicians & $-.22^{* *}$ & $-.22^{* *}$ & $.16^{* *}$ & $.55^{* *}$ & - & $-.43^{* *}$ & $-.45^{* *, a}$ \\
\hline & Medical students & -.09 & -.10 & .03 & $.52^{* * *}$ & - & $-.45^{* * * a}$ & $-.40^{* * *}$ \\
\hline \multirow[t]{3}{*}{ Quality of life } & Nurses & .02 & .05 & .05 & $-.11^{* *}$ & $-.36^{* *}$ & - & $.43^{* *, b}$ \\
\hline & Physicians & -.03 & -.03 & $-.14^{* *}$ & $-.30^{* *}$ & $-.43^{* * *}$ & - & $.32^{* *, \mathrm{a}}$ \\
\hline & Medical students & .00 & $.10^{*}$ & $.15^{* *}$ & $-.31^{* *}$ & $-.45^{* *}$ & - & $.38^{* *}$ \\
\hline \multirow[t]{3}{*}{ Self-compassion } & Nurses & $.17^{* * *}$ & $.14^{* * *}$ & $-.08^{*}$ & -.06 & $-.36^{* * *}$ & $.43^{* *}$ & - \\
\hline & Physicians & $.22^{* *}$ & $.22^{* * *}$ & $-.10^{*}$ & $-.20^{* *}$ & $-.45^{* *}$ & $.32^{* *}$ & - \\
\hline & Medical students & $.14^{* * *}$ & $.15^{* * *}$ & $-.12^{*}$ & $-.21^{* *}$ & $-.40^{* *}$ & $.39^{* * *}$ & - \\
\hline
\end{tabular}

$* p<0.05$

$* * p<0.01$

${ }^{\#}$ Spearman's Rank-Order correlation; sex coded such that $0=$ male and $1=$ female

${ }^{\text {a }}$ Different from nurses

${ }^{\mathrm{b}}$ Different from physicians

${ }^{\mathrm{c}}$ Different from medical students at $p<.05$, using Fisher $r$-to- $z$ transformation

\section{Primary Results}

Nurses: Burnout At Step 1, the regression model explained $37.72 \%$ of the variance in burnout in nurses, $F(4,796)=$ $120.54, p<.01$. Lower experience $(\beta=-0.13, p<.01)$, greater stress $(\beta=0.47, p<.01)$, and lower self-compassion $(\beta=-$ $0.31, p<.01)$ predicted greater burnout. At Step 2 , the interaction between stress and self-compassion was added to the model. The model then explained $38.28 \%$ of the variance in burnout, $F(5,795)=98.63, p<.01$, an increase of $0.56 \%$, $R^{2} \Delta=0.01, F \Delta(1795)=7.22, p<.01$. Having less clinical experience and lower self-compassion continued to predict greater burnout; while the interaction between stress and self-compassion was also significant. In contrast to expectation, however, the association between stress and burnout was stronger (having a steeper slope) in those with greater selfcompassion (see Table 3; Fig. 1). Interpretatively, the protective effect of greater self-compassion was reduced at higher levels of stress.
Nurses: Quality of Life At Step 1, the regression model explained $19.75 \%$ of the variance in QOL among nurses, $F(4,796)=48.99, p<.01$. Being female $(\beta=0.08, p=.011)$, lower stress $(\beta=-0.08, p=.010)$, and greater selfcompassion $(\beta=0.43, p<.01)$ predicted greater QOL. At Step 2, the model explained $19.80 \%$ of the variance in QOL, $F(5,795)=39.25, p<.01$, a non-significant increase of $0.05 \%$, $R^{2} \Delta=0.00, F \Delta(1795)=0.44, p=.506$. Being female and greater self-compassion continued to predict greater $\mathrm{QOL}$, while the interaction between stress and self-compassion was non-significant, indicating that the association between stress and QOL did not vary as a function of selfcompassion in nurses (Table 3).

Physicians: Burnout At Step 1, the regression model explained $44.09 \%$ of the variance in burnout in physicians, $F(4,511)=$ $100.72, p<.01$. Having lower experience $(\beta=-0.11$, $p<.01)$, greater stress $(\beta=0.47, p<.01)$, and lower selfcompassion $(\beta=-0.33, p<.01)$ predicted greater burnout. 
At Step 2, the model explained $44.13 \%$ of the variance in burnout, $F(5,510)=80.58, p<.01$, a non-significant increase of $0.04 \%, R^{2} \Delta=0.00, F \Delta(1510)=0.45, p=.502$. Having less experience, greater stress, and lower self-compassion continued to predict greater burnout, while the interaction between stress and self-compassion was non-significant, indicating that the association between stress and burnout did not vary as a function of self-compassion in physicians (Table 3).

Physicians: Quality of Life At Step 1, the regression model explained $17.91 \%$ of the variance in QOL among physicians, $F(4,511)=27.88, p<.01$. Being male $(\beta=-0.08, p=.040)$, lower experience $(\beta=-0.12, p<.01)$, lower stress $(\beta=-0.24$, $p<.01)$, and greater self-compassion $(\beta=0.29, p<.01)$ predicted greater QOL. At Step 2, the model explained $17.92 \%$ of the variance in $\mathrm{QOL}, F(5,510)=22.28, p<.01$, a non-significant increase of $0.01 \%, R^{2} \Delta=0.00, F \Delta(1510)=0.06, p=.802$. Being male, having less clinical experience, and greater selfcompassion continued to predict greater QOL, while the interaction between stress and self-compassion was non-significant, indicating that the association between stress and QOL did not vary as a function of self-compassion in physicians (Table 3).

Medical Students: Burnout At Step 1, the regression model explained $37.97 \%$ of the variance associated with burnout in medical students, $F(4,348)=53.26, p<.01$. Greater stress $(\beta=0.47, p<.01)$ and lower self-compassion $(\beta=-0.32$, $p<.01)$ predicted greater burnout. At Step 2 , the model explained $38.28 \%$ of the variance in burnout, $F(5,347)=43.05$, $p<.01$, a non-significant increase of $0.31 \%, R^{2} \Delta=0.00$, $F \Delta(1347)=1.76, p=.185$. Lower self-compassion continued

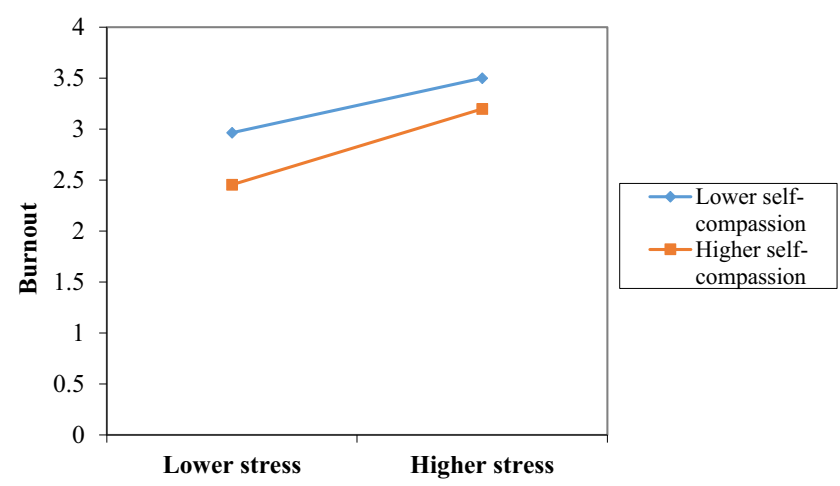

Fig. 1 A graphical demonstration of the moderating effect of selfcompassion on the relationship between stress and burnout in nurses

to predict greater burnout, while the interaction was non-significant, indicating that the association between stress and burnout did not vary as a function of self-compassion in medical students (Table 4).

Medical Students: Quality of Life At Step 1, the regression model explained $25.66 \%$ of the variance associated with QOL in medical students, $F(4,348)=30.03, p<.01$. Being female $(\beta=0.23, p<.01)$, reporting lower experience $(\beta=-0.12$, $p<.01)$, lower stress $(\beta=-0.27, p<.01)$, and greater selfcompassion $(\beta=0.35, p<.01)$ predicted greater QOL. At Step 2, the model explained $25.67 \%$ of the variance in QOL, $F(5,347)=23.97, p<.01$, a non-significant increase of $0.01 \%$, $R^{2} \Delta=0.00, F \Delta(1347)=0.03, p=.863$. Being female and reporting greater self-compassion continued to predict greater QOL, while the interaction between stress and self-compassion was non-significant, indicating that the association between

Table 3 Multivariate predictors of burnout and quality of life in nurses and physicians (step 2 of regressions)

\begin{tabular}{|c|c|c|c|c|c|c|c|c|c|}
\hline Sample & & B & $\begin{array}{l}\text { Standard } \\
\text { error }\end{array}$ & $\begin{array}{l}\text { Standardized } \\
\text { beta }\end{array}$ & $\begin{array}{l}\text { Squared part } \\
\text { correlations }\end{array}$ & $\mathrm{B}$ & $\begin{array}{l}\text { Standard } \\
\text { error }\end{array}$ & $\begin{array}{l}\text { Standardized } \\
\text { beta }\end{array}$ & $\begin{array}{l}\text { Squared part } \\
\text { correlations }\end{array}$ \\
\hline & & \multicolumn{4}{|c|}{ Burnout } & \multicolumn{4}{|c|}{ Quality of Life } \\
\hline \multirow{6}{*}{$\begin{array}{l}\text { Nursing } \\
\text { sample }\end{array}$} & (Constant) & 4.00 & 0.18 & & & 1.29 & 0.42 & & \\
\hline & ${ }^{\#} \operatorname{Sex}$ & -0.06 & 0.08 & -0.02 & 0.0005 & 0.46 & 0.18 & $0.08^{*}$ & 0.0066 \\
\hline & Experience & -0.01 & 0.00 & $-0.13 * *$ & 0.0153 & 0.00 & 0.00 & -0.02 & 0.0006 \\
\hline & Stress & 0.08 & 0.11 & 0.11 & 0.0005 & 0.03 & 0.25 & 0.02 & 0.0000 \\
\hline & Self-compassion & -0.32 & 0.03 & $-0.32 * *$ & 0.0989 & 0.88 & 0.07 & $0.44 * *$ & 0.1802 \\
\hline & $\begin{array}{l}\text { Self-compassion } \times \\
\text { Stress }\end{array}$ & 0.09 & 0.03 & $0.37 * *$ & 0.0056 & -0.05 & 0.07 & -0.10 & 0.0004 \\
\hline \multirow{6}{*}{$\begin{array}{r}\text { Physician } \\
\text { sample }\end{array}$} & (Constant) & 3.51 & 0.12 & & & 4.25 & 0.31 & & \\
\hline & ${ }^{\#} \operatorname{Sex}$ & 0.05 & 0.04 & 0.05 & 0.0021 & -0.21 & 0.10 & $-0.08^{*}$ & 0.0068 \\
\hline & Experience & -0.01 & 0.00 & $-0.11 * *$ & 0.0115 & -0.01 & 0.00 & $-0.12 * *$ & 0.0128 \\
\hline & Stress & 0.43 & 0.12 & $0.58 * *$ & 0.0140 & -0.47 & 0.32 & -0.29 & 0.0035 \\
\hline & Self-compassion & -0.27 & 0.03 & $-0.33 * *$ & 0.0985 & 0.53 & 0.08 & $0.29 * *$ & 0.0755 \\
\hline & $\begin{array}{l}\text { Self-compassion } \times \\
\text { Stress }\end{array}$ & -0.02 & 0.04 & -0.11 & 0.0005 & 0.02 & 0.10 & 0.05 & 0.0001 \\
\hline
\end{tabular}

Note. ${ }^{*} p<0.05, * * p<0.01 ;{ }^{*}$ sex coded such that $0=$ male and $1=$ female. Sample $1=$ Nurses, $2=$ Physicians 
Table 4 Multivariate predictors of burnout and quality of life in medical students (step 2 of regressions)

\begin{tabular}{lllll}
\hline & B & Standard error & Standardized beta & Squared part correlations \\
\hline & Burnout & & & \\
(Constant) & 3.50 & 0.15 & & \\
\#Sex & -0.07 & 0.05 & -0.06 & 0.0040 \\
Experience & 0.01 & 0.03 & 0.02 & 0.0003 \\
Stress & 0.17 & 0.16 & 0.22 & 0.0021 \\
Self-compassion & -0.23 & 0.04 & $-0.29^{* *}$ & 0.0567 \\
Self-compassion $\times$ Stress & 0.07 & 0.05 & 0.27 & 0.0031 \\
& Quality of Life & & \\
(Constant) & 2.29 & 0.36 & & 0.0502 \\
\#Sex & 0.57 & 0.12 & $0.23^{* *}$ & 0.0001 \\
Experience & 0.02 & 0.07 & 0.01 & 0.0042 \\
Stress & -0.55 & 0.39 & -0.31 & 0.0859 \\
Self-compassion & 0.63 & 0.10 & $0.35^{* *}$ & 0.0001 \\
Self-compassion $\times$ Stress & 0.02 & 0.13 & 0.04 & \\
\hline
\end{tabular}

Note. ${ }^{*} p<0.05,{ }^{*} p<0.01 ;{ }^{*}$ sex coded such that $0=$ male and $1=$ female stress and QOL did not vary as a function of self-compassion in medical students (Table 4).

\section{Discussion}

In extending prior research examining how stress may contribute to burnout and impaired QOL in healthcare worker populations and testing for possible protective factors, this study found the expected association in which greater stress predicted greater burnout and lower QOL in all three groups, albeit with some variation in magnitude. In seeking to identify resiliency-type factors that might buffer against the ill-effects of stress, analyses suggested that greater self-compassion consistently predicted lower burnout and greater QOL in all three groups although the magnitude of this association did vary. However, selfcompassion only moderated the relationship between stress and burnout in the nursing sample and did so in a counterintuitive direction; surprisingly, the 'protective' effect of selfcompassion was reduced at higher levels of stress in this group. Below, these findings are revisited in relation to prior literature, some preliminary interpretations are offered, study limitations are discussed, and directions for future study are given.

In terms of the primary findings, greater stress predicted greater burnout and lower QOL across samples of physicians, nurses, and medical students. Prior studies have also found that stress predicts greater burnout (Visser et al. 2003), and lower QOL (Su et al. 2009). Equally consistent with previous literature, self-compassion predicted lower stress (Neely et al. 2009), lower burnout (Alkema et al. 2008), and greater QOL (Van Dam Sheppard, Forsyth, \& Earleywine, 2010) across groups, although the strength of the associations varied somewhat. Theory suggests that more self-compassionate individuals manage stress more effectively (Alkema et al. 2008;
Vigna, Poehlmann-Tynan, \& Koenig 2017), potentially via a greater reliance on positive cognitive restructuring and less avoidance and escape (Allen \& Leary 2010), a greater ability to disengage from unfruitful goal pursuit and redirect energy towards alternative goals (Neely et al. 2009), greater selfacceptance and kindness in the face of perceived inadequacy (Neely et al. 2009), and/or more balanced, adaptive and flexible coping strategies (Kyeong 2013; Sirois, Molnar, \& Hirsch 2015). Although these data are cross-sectional and the exact mechanisms remain unclear, self-compassion consistently predicted better outcomes in all three samples of healthcare workers, suggesting it may be a useful target for intervention in these highly stressed groups.

Less consistent with previous evidence demonstrating the potency of self-compassion as a mitigator of negative outcomes (Alkema et al. 2008), was the finding that while selfcompassion moderated the relationship between stress and burnout in the nursing sample, it did so in a counterintuitive manner. Rather than weakening the association between stress and burnout, this association was stronger amongst nurses. In considering this finding further, it is important to consider both (a) why moderation was present in nurses but not in other groups, and (b) why self-compassion strengthened (rather than weakened) the association.

While little is known about self-compassion in the healthcare professions, it may be that this finding reflects differences between nursing and medicine. Broadly speaking, self-compassion may be considered more important in nursing. Relative to medicine, nursing has been described as having a more compassionfocussed professional culture (Boyle 2011), with other important differences in power and status (Daiski 2004) and the modal personality types gravitating towards the two professions (Hardigan \& Cohen 1999). Such differences may help create or reinforce differences in how important self-compassion is seen as 
being, how it viewed, and thus how it relates to outcomes across different professional groups. Equally, because compassion is arguably more central to nursing, it may be that nurses are better equipped or trained to recognize the extent to which they are (or are not) being compassionate towards themselves and can provide more accurate self-compassion-related self-report data.

Additionally, given that nurses reported greater levels of burnout than physicians and medical students and selfcompassion was more closely associated with burnout at the univariate level amongst nurses, it may be that self-compassion has a greater level of burnout to 'work with' (statistically speaking), allowing the moderation to be significant. However, the fact that the protective effect of self-compassion on stress was reduced at higher stress levels suggests such an interpretation to be unlikely or, at least, incomplete. Finally, although participant sex was covaried in analyses, sex differences in psychological characteristics may also be important. Women generally report lower self-compassion (Neff \& McGehee 2010), greater stress (Matud 2004) and greater burnout (Linzer et al. 2002) than men. Thus, because the nursing sample in the current study was primarily female $(93.90 \%)$, it is unclear whether the patterns observed in the nursing sample reflect its gender composition or factors specific to nursing itself.

More broadly, it is worth underscoring the fact that prior studies have typically shown that self-compassion weakens the association between 'negative' elements of psychological functioning and either psychological (Körner et al. 2015) or physical health outcomes (Friis et al. 2015). As noted, however, other studies have found different patterns of moderation. In one study, for example, self-compassion moderated the relationship between academic burnout and psychological well-being such that an association was more strongly evident at higher levels of self-compassion (Kyeong 2013). In accordance with this study, and contrary to our expectations, greater self-compassion was associated with a stronger relationship between stress and burnout in the current study.

Given the absence of data linking self-compassion to outcomes in samples of this kind, the reasons for such an association are unclear. In beginning to understand and interpret these findings, it is worth recalling univariate differences in the correlates of experience, sex, and self-compassion across the three groups. Specifically, greater experience was only associated with greater QOL in students, but not nurses or physicians, and was associated with lower stress in nurses and medical students, but not physicians. Equally, selfcompassion was associated with lower stress in medical students and physicians, but not nurses (see Table 2). Additional differences were found in the magnitude of the association amongst the constructs measured here, with global differences broadly evidenced between nurses versus those from a medical background (physicians and medical trainees). Thus, even at the univariate level, differences in how self-compassion and stress related to other variables were seen.
Interpretatively, two possibilities are evident. First, it may be that self-compassion is differentially associated with perfectionist traits (Neff, Rude, \& Kirkpatrick 2007; Stoeber, Otto, \& Dalbert 2009) in nurses, that some nurses fail to recognize their lack of self-kindness (Neff 2003a), or that data reflect a tendency for more self-compassionate nurses to view themselves as 'omnipotent rescuers' (Benson \& Magraith 2005). Evidence suggests that 'obsessively passionate' people are prone to believing that self-compassion could lead to weakness and mediocrity or prevent them from attaining their goals (Gilbert \& Procter 2006; Sutherland et al. 2014). Hence, it may be that 'obsessive passion' in nurses leads to a portion of this sample feeling (or reporting) less burnt out as a result (Schellenberg et al. 2019).

Second, it may be that the sources of stress systematically differ across the three samples. As noted, nurses typically have lower status and control in their working environments and it may be that the sources of stress (e.g., patients, clinical duties, schedules, management) are such that self-kindness is not of benefit. In such a case, the importance of receiving compassion from others should be emphasized further, given its effectiveness in buffering against the depressive effects of self-criticism (Hermanto et al. 2016). Prior work clearly demonstrates that the effects of controllable vs. uncontrollable stress are different (Breier et al. 1987), perhaps because control perceptions lead to the belief that future threats can be minimized (Miller 1979). For example, it has been shown that it is uncontrollable (rather than controllable) events that best predict illness (Stern, McCants, \& Pettine 1982). Although there was no direct measure of controllability in this study, stress was less closely linked to QOL and selfcompassion in nurses (Table 2) perhaps implying that the stressors being experienced by nurses differ in some way from those experienced by doctors or medical students. Thus, while nurses report greater stress and burnout, it may be that their stressors are differentially comprised of events (e.g., administrative complexities, competing job demands, patient issues) over which they have little control. Prima facie, managing the self's response to certain types of internal difficulties via self-compassion may be more relevant or efficacious than for 'events' that have a greater external component or are inherently less controllable.

\section{Limitations and Future Research Directions}

Although this study makes several useful contributions to the literature and employs a large sample, the extent to which findings will generalize to other populations of healthcare professionals is unclear. The study also has a few major limitations - a reliance on self-report measures, use of a cross-sectional and observational design, use of a nonstandardized three-item measure of work stress, and the absence of measurement specifically identifying the particular 
types of stress and self-compassion of relevance. Reliance on self-report may inflate the associations amongst measures (Podsakoff, MacKenzie, \& Podsakoff 2012) and measures of work stress, burnout, QOL, and self-compassion may be subject to social desirability, self-presentational, and recall biases (Podsakoff \& Organ 1986; Podsakoff et al. 2012). Although self-compassion and QOL may be difficult to access outside of-self-report, alternate measures such as the ImplicitAssociation Test (Greenwald, McGhee, \& Schwartz 1998) or behavioural measures are worth considering. The crosssectional and observational design does not allow the direction of causation in the associations between stress, burnout, QOL, and self-compassion to be determined. The nonstandardized (but face valid) three-item measure of work stress used in the study might not possess the same level of construct or content validity as a broader or more extensively validated measures of stress (such as the Perceived Stress Scale; Cohen 1994) and different types of stress might be more or less usefully managed with self-compassion. Future studies examining the possible stress-moderating effects of self-compassion in healthcare would benefit from incorporating standardized stress measures capturing different types of stress.

Finally, because the short form of the SCS was employed, analyses were unable to evaluate the possibility that specific elements of either stress or self-compassion are relevant. Of the two, focussing on the specific elements of self-compassion is especially important, given that there are several major ways in which it can be conceptualized (i.e., kindness, common humanity and mindfulness; Germer \& Neff 2013), with evidence also indicating that compassion and kindness too may be distinct constructs (Gilbert, Basran, MacArthur, \& Kirby 2019). It is also possible that the observed interaction (or lack thereof) between self-compassion and stress in predicting outcomes may be different for different elements of the global self-compassion construct and/or various types of stress. These would be fertile avenues for future research, along with (a) a deeper consideration of how specialization is relevant to the professional dynamics linking stress and self-compassion to outcomes, and (b) a focus on fears regarding selfcompassion (e.g., Hermanto et al. 2016; Miron, Sherrill, \& Orcutt 2015).

In summary, despite its limitations and unexpected findings, the study contributes to existing studies by (a) documenting the associations between stress, burnout, QOL, and self-compassion in large samples of healthcare personnel and (b) testing for variation in the moderating effect of selfcompassion across professions. In documenting these findings, the study may also contribute towards raising awareness in health professionals regarding the ways in which their stress may manifest itself in their professional practice and how selfcompassion may (and may not) facilitate more effective stress management.
Author Contributions VD analysed the data and collaborated in the design and writing of the study. ATF coordinated the data collection process and collaborated in design and the writing of the study. NSC collaborated in, and supervised, design, data analysis, and study write-up.

\section{Compliance with Ethical Standards}

The authors declare that they have no conflict of interest. All procedures performed in the three studies involving human participants were in accordance with the ethical standards of the institutional research committee (University of Auckland Human Participants Ethics Committee; Reference number: 7640) and with the 1964 Helsinki declaration and its later amendments or comparable ethical standards. General support for the studies was provided by the University of Auckland; however, the organization had no direct input into study design, research questions, data collection, analyses, or interpretation. Informed consent was obtained from all individual participants included in the three studies.

\section{References}

Alkema, K., Linton, J. M., \& Davies, R. (2008). A study of the relationship between self-care, compassion satisfaction, compassion fatigue, and burnout among hospice professionals. Journal of Social Work in End-of-Life \& Palliative Care, 4, 101-119. https://doi.org/10.1080/ 15524250802353934.

Allen, A. B., \& Leary, M. R. (2010). Self-compassion, stress, and coping. Social and Personality Psychology Compass, 4, 107-118. https:// doi.org/10.1111/j.1751-9004.2009.00246.x.

Anagnostopoulos, F., \& Niakas, D. (2010). Job burnout, health-related quality of life, and sickness absence in Greek health professionals. European Psychologist, 15, 132-141. https://doi.org/10.1027/10169040/a000013.

Benson, J., \& Magraith, K. (2005). Compassion fatigue and burnout: the role of Balint groups. Australian Family Physician, 34, 497-498. https://doi.org/10.2267/0300-8495.34.6.1815.

Boyle, D. A. (2011). Countering compassion fatigue: a requisite nursing agenda. Online Journal of Issues in Nursing, 16, 1B. https://doi.org/ 10.3912/OJIN.Vol16No01Man02.

Breier, A., Albus, M., Pickar, D., Zahn, T. P., Wolkowitz, O. M., \& Paul, S. M. (1987). Controllable and uncontrollable stress in humans: Alterations in mood and neuroendocrine and psychophysiological function. American Journal of Psychiatry, 144, 1419-1425. https:// doi.org/10.1176/ajp.144.11.1419.

Cohen, S. (1994). Perceived stress scale. United States of America: Mind Garden, Inc.

Coomber, S., Todd, C., Park, G., Baxter, P., Firth-Cozens, J., \& Shore, S. (2002). Stress in UK intensive care unit doctors. British Journal of Anaesthesia, 89, 873-881. https://doi.org/10.1093/bja/aef273.

Daiski, I. (2004). Changing nurses' dis-empowering relationship patterns. Journal of Advanced Nursing, 48, 43-50. https://doi.org/10.1111/j. 1365-2648.2004.03167.x.

Dawson, J. F. (2013). Interpreting interaction effects. Retrieved from http://www.jeremydawson.co.uk/slopes.htm. Accessed 4 Feb 2019.

de Zulueta, P. (2013). Compassion in 21st century medicine: is it sustainable? Clinical Ethics, 8, 119-128. https://doi.org/10.1177/ 1477750913502623.

Degeling, P., Kennedy, J., \& Hill, M. (2001). Mediating the cultural boundaries between medicine, nursing and management - the central challenge in hospital reform. Health Services Management Research, 14, 36-48. https://doi.org/10.1258/0951484011912519.

Dellve, L., \& Wikström, E. (2009). Managing complex workplace stress in health care organizations: leaders' perceived legitimacy conflicts. 
Journal of Nursing Management, 17, 931-941. https://doi.org/10. 1111/j.1365-2834.2009.00996.x.

Dev, V., Fernando, A. T., Lim, A., \& Consedine, N. S. (2018). Does selfcompassion mitigate the relationship between burnout and barriers to compassion? A cross-sectional quantitative study of 799 nurses. International Journal of Nursing Studies, 81, 81-88. https://doi.org/ 10.1016/j.jinurstu.2018.02.003.

Dev, V., Fernando, A. T., Kirby, J. N., \& Consedine, N. S. (2019). Variation in the barriers to compassion across healthcare training and disciplines: a cross-sectional study of doctors, nurses, and medical students. International Journal of Nursing Studies, 90, 1-10. https://doi.org/10.1016/j.jnurstu.2018.09.015.

Diener, E., Emmons, R. A., Larsen, R. J., \& Griffin, S. (1985). The 'Satisfaction with life Scale'. Journal of Personality Assessment, 49, 71-75. https://doi.org/10.1207/s15327752jpa4901_13.

Dollard, M. F., \& Winefield, A. H. (1996). Managing occupational stress: a national and international perspective. International Journal of Stress Management, 3, 69-83. https://doi.org/10.1007/ BF01857716.

Duarte, J., Pinto-Gouveia, J., \& Cruz, B. (2016). Relationships between nurses' empathy, self-compassion and dimensions of professional quality of life: a cross-sectional study. International Journal of Nursing Studies, 60, 1-11. https://doi.org/10.1016/j.ijnurstu.2016. 02.015 .

Eltarhuni, A. (2016). Job stress sources among doctors and nurses working in emergency departments in public hospitals. Journal of Nursing and Health Science, 5, 84-88.

Fernando, A. T., \& Consedine, N. S. (2014). Beyond compassion fatigue: the transactional model of physician compassion. Journal of Pain and Symptom Management, 48, 289-298. https://doi.org/10.1016/j. jpainsymman.2013.09.014.

Fernando, A. T., \& Consedine, N. S. (2017). Barriers to medical compassion as a function of experience and specialization: psychiatry, pediatrics, internal medicine, surgery, and general practice. Journal of Pain and Symptom Management, 53, 979-987. https://doi.org/10. 1016/j.jpainsymman.2016.12.324.

Folkman, S. (2013). Stress: appraisal and coping. In M. D. Gellman, \& J. R. Turner (Eds.), Encyclopedia of behavioral medicine (pp. 19131915). New York, NY: Springer New York. doi:https://doi.org/10. 1007/978-1-4419-1005-9 215.

Friis, A. M., Johnson, M. H., Cutfield, R. G., \& Consedine, N. S. (2015). Does kindness matter? Self-compassion buffers the negative impact of diabetes-distress on HbA1c. Diabetic Medicine, 32, 1634-1640. https://doi.org/10.1111/dme.12774.

Fry, M., MacGregor, C., Ruperto, K., Jarrett, K., Wheeler, J., Fong, J., \& Fetchet, W. (2013). Nursing praxis, compassionate caring and interpersonal relations: an observational study. Australasian Emergency Nursing Journal, 16, 37. https://doi.org/10.1016/j.aenj.2013.02.003.

Germer, C. K., \& Neff, K. D. (2013). Self-compassion in clinical practice. Journal of Clinical Psychology, 69, 856-867. https://doi.org/10. 1002/jclp.22021.

Gilbert, P., \& Procter, S. (2006). Compassionate mind training for people with high shame and self-criticism: overview and pilot study of a group therapy approach. Clinical Psychology \& Psychotherapy, 13, 353-379. https://doi.org/10.1002/cpp.507.

Gilbert, P., Basran, J., MacArthur, M., \& Kirby, J. (2019). Differences in the semantics of prosocial words: an exploration of compassion and kindness. Mindfulness, 10, 2259-2271. https://doi.org/10.1007/ s12671-019-01191-x.

Greenwald, A. G., McGhee, D. E., \& Schwartz, J. L. K. (1998). Measuring individual differences in implicit cognition: the implicit association test. Journal of Personality and Social Psychology, 74, 1464-1480. https://doi.org/10.1037//0022-3514.74.6.1464.

Happell, B., Dwyer, T., Reid-Searl, K., Burke, K. J., Caperchione, C. M., \& Gaskin, C. J. (2013). Nurses and stress: recognizing causes and seeking solutions. Journal of Nursing Management, 21, 638-647. https://doi.org/10.1111/jonm.12037.

Hardigan, P. C., \& Cohen, S. R. (1999). A comparison of osteopathic, pharmacy, physical therapy, physician assistant, and occupational therapy students' personality styles: implications for education and practice. Journal of Pharmacy Teaching, 7, 67-79. https://doi.org/ 10.3109/J060v07n02 07.

Hermanto, N., Zuroff, D. C., Kopala-Sibley, D. C., Kelly, A. C., Matos, M., Gilbert, P., \& Koestner, R. (2016). Ability to receive compassion from others buffers the depressogenic effect of self-criticism: a cross-cultural multi-study analysis. Personality and Individual Differences, 98, 324-332. https://doi.org/10.1016/j.paid.2016.04. 055.

Horsburgh, M., Perkins, R., Coyle, B., \& Degeling, P. (2006). The professional subcultures of students entering medicine, nursing and pharmacy programmes. Journal of Interprofessional Care, 20 , 425-431. https://doi.org/10.1080/13561820600805233.

Isikhan, V., Comez, T., \& Zafer Danis, M. (2004). Job stress and coping strategies in health care professionals working with cancer patients. European Journal of Oncology Nursing, 8, 234-244. https://doi.org/ 10.1016/j.ejon.2003.11.004.

Jackson, S. H. (1999). The role of stress in anaesthetists' health and wellbeing. Acta Anaesthesiologica Scandinavica, 43, 583-602. https:// doi.org/10.1034/j.1399-6576.1999.430601.x.

Kalichman, S. C., Gueritault-Chalvin, V., \& Demi, A. (2000). Sources of occupational stress and coping strategies among nurses working in AIDS care. Journal of the Association of Nurses in AIDS Care, 11, 31-37. https://doi.org/10.1016/S1055-3290(06)60274-4.

Körner, A., Coroiu, A., Copeland, L., Gomez-Garibello, C., Albani, C., Zenger, M., \& Brähler, E. (2015). The role of self-compassion in buffering symptoms of depression in the general population. PLoS One, 10, e0136598. https://doi.org/10.1371/journal.pone.0136598.

Kristensen, T. S., Borritz, M., Villadsen, E., \& Christensen, K. B. (2005). The Copenhagen burnout inventory: a new tool for the assessment of burnout. Work \& Stress, 19, 192-207. https://doi.org/10.1080/ 02678370500297720.

Kyeong, L. W. (2013). Self-compassion as a moderator of the relationship between academic burn-out and psychological health in Korean cyber university students. Personality and Individual Differences, 54, 899-902. https://doi.org/10.1016/j.paid.2013.01.001.

Law, B. Y., \& Chan, E. A. (2015). The experience of learning to speak up: a narrative inquiry on newly graduated registered nurses. Journal of Clinical Nursing, 24, 1837-1848. https://doi.org/10.1111/jocn. 12805.

Linzer, M., McCurray, J. E., Visser, M., Oort, F. J., Smets, E. M. A., \& de Haes, H. C. (2002). Sex differences in physician burnout in the United States and the Netherlands. Journal of the American Medical Women's Association, 57, 191-193.

Lowry, R. (2018). Significance of the difference between two correlation coefficients. Retrieved from http://vassarstats.net/rdiff.html. Accessed 25 Jan 2019.

MacBeth, A., \& Gumley, A. (2012). Exploring compassion: a metaanalysis of the association between self-compassion and psychopathology. Clinical Psychology Review, 32, 545-552. https://doi.org/ 10.1016/j.cpr.2012.06.003.

Mantzoukas, S., \& Jasper, M. A. (2004). Reflective practice and daily ward reality: a covert power game. Journal of Clinical Nursing, 13, 925-933. https://doi.org/10.1111/j.1365-2702.2004.01008.x.

Matud, M. P. (2004). Gender differences in stress and coping styles. Personality and Individual Differences, 37, 1401-1415. https://doi. org/10.1016/j.paid.2004.01.010.

McManus, I. C., Winder, B. C., \& Gordon, D. (2002). The causal links between stress and burnout in a longitudinal study of UK doctors. The Lancet, 359, 2089-2090. https://doi.org/10.1016/S01406736(02)08915-8. 
Mead, N., \& Bower, P. (2000). Patient-centredness: a conceptual framework and review of the empirical literature. Social Science \& Medicine, 51, 1087-1110. https://doi.org/10.1016/S0277-9536(00) 00098-8.

Michel, G., Bisegger, C., Fuhr, D. C., \& Abel, T. (2009). Age and gender differences in health-related quality of life of children and adolescents in Europe: a multilevel analysis. Quality of Life Research, 18, 1147-1157. https://doi.org/10.1007/s11136-009-9538-3.

Miller, S. M. (1979). Controllability and human stress: method, evidence and theory. Behaviour Research and Therapy, 17, 287-304. https:// doi.org/10.1016/0005-7967(79)90001-9.

Miron, L. R., Sherrill, A. M., \& Orcutt, H. K. (2015). Fear of selfcompassion and psychological inflexibility interact to predict PTSD symptom severity. Journal of Contextual Behavioral Science, 4, 37-41. https://doi.org/10.1016/j.jcbs.2014.10.003.

Moltu, C., Binder, P., \& Nielsen, G. H. (2010). Commitment under pressure: experienced therapists' inner work during difficult therapeutic impasses. Psychotherapy Research, 20, 309-320. https://doi.org/10. 1080/10503300903470610.

Nakamura, H., Nagase, H., Yoshida, M., \& Ogino, K. (1999). Natural killer (NK) cell activity and NK cell subsets in workers with a tendency of burnout. Journal of Psychosomatic Research, 46, 569-578. https://doi.org/10.1016/S0022-3999(99)00009-4.

Neely, M., Schallert, D., Mohammed, S., Roberts, R., \& Chen, Y. (2009). Self-kindness when facing stress: the role of self-compassion, goal regulation, and support in college students' well-being. Motivation and Emotion, 33, 88-97. https://doi.org/10.1007/s11031-008-91198.

Neff, K. (2003a). The development and validation of a scale to measure self-compassion. Self and Identity, 2, 223-250. https://doi.org/10. 1080/15298860309027.

Neff, K. (2003b). Self-compassion: an alternative conceptualization of a healthy attitude toward oneself. Self and Identity, 2, 85-101. https:// doi.org/10.1080/15298860309032.

Neff, K. (2016). The self-compassion scale is a valid and theoretically coherent measure of self-compassion. Mindfulness, 7, 264-274. https://doi.org/10.1007/s12671-015-0479-3.

Neff, K., \& McGehee, P. (2010). Self-compassion and psychological resilience among adolescents and young adults. Self and Identity, 9, 225-240. https://doi.org/10.1080/15298860902979307.

Neff, K., Rude, S. S., \& Kirkpatrick, K. L. (2007). An examination of self-compassion in relation to positive psychological functioning and personality traits. Journal of Research in Personality, 41, 908916. https://doi.org/10.1016/j.jrp.2006.08.002.

Perkins, R. J., Horsburgh, M., \& Coyle, B. (2008). Attitudes, beliefs and values of students in undergraduate medical, nursing and pharmacy programs. Australian Health Review, 32, 252-255. https://doi.org/ 10.1071/AH080252.

Podsakoff, P. M., \& Organ, D. W. (1986). Self-reports in organizational research: problems and prospects. Journal of Management, 12, 531544. https://doi.org/10.1177/014920638601200408.

Podsakoff, P. M., MacKenzie, S. B., \& Podsakoff, N. P. (2012). Sources of method bias in social science research and recommendations on how to control it. Annual Review of Psychology, 63, 539-569. https://doi.org/10.1146/annurev-psych-120710-100452.

Raes, F., Pommier, E., Neff, K. D., \& Van Gucht, D. (2011). Construction and factorial validation of a short form of the self-compassion scale. Clinical Psychology \& Psychotherapy, 18, 250-255. https://doi.org/ 10.1002/cpp.702.

Ramirez, A. J., Graham, J., Richards, M. A., Gregory, W. M., \& Cull, A. (1996). Mental health of hospital consultants: the effects of stress and satisfaction at work. The Lancet, 347, 724-728. https://doi.org/ 10.1016/S0140-6736(96)90077-X.

Richards, D. A., Meakins, J., Tawfik, J., Godfrey, L., Dutton, E., Richardson, G., \& Russell, D. (2002). Nurse telephone triage for same day appointments in general practice: multiple interrupted time series trial of effect on workload and costs. BMJ, 325, 1214-1217. https://doi.org/10.1136/bmj.325.7374.1214

Robinson, E., Denny, S., Milfont, T., Merry, S., \& Ameratunga, S. (2008). Burnout and wellbeing: testing the Copenhagen burnout inventory in New Zealand teachers. Social Indicators Research, 89, 169-177. https://doi.org/10.1007/s11205-007-9229-9.

Schellenberg, B., Mosewich, A., Bailis, D., Gaudreau, P., \& VernerFilion, J. (2019). When self-compassion loses its luster: ratings of self-compassionate and self-critical responding among passionate students. PsyArXiv Preprints, 0, 1-30. https://doi.org/10.31234/ osf.io/vk7n3.

Senol-Durak, E., Durak, M., \& Gencoz, T. (2010). Psychometric properties of the satisfaction with life scale among Turkish university students, correctional officers, and elderly adults. Social Indicators Research, 99, 413-429. https://doi.org/10.1007/s11205-010-95894.

Shapiro, S. L., Brown, K. W., \& Biegel, G. M. (2007). Teaching self-care to caregivers: effects of mindfulness-based stress reduction on the mental health of therapists in training. Training and Education in Professional Psychology, 1, 105-115. https://doi.org/10.1037/19313918.1.2.105.

Sinclair, S., Raffin-Bouchal, S., Venturato, L., Mijovic-Kondejewski, J., \& Smith-MacDonald, L. (2017). Compassion fatigue: a metanarrative review of the healthcare literature. International Journal of Nursing Studies, 69, 9-24. https://doi.org/10.1016/j.ijnurstu. 2017.01.003.

Sirois, F. M., Molnar, D. S., \& Hirsch, J. K. (2015). Self-compassion, stress, and coping in the context of chronic illness. Self and Identity, 14, 334-347. https://doi.org/10.1080/15298868.2014.996249.

Soysa, C. K., \& Wilcomb, C. J. (2015). Mindfulness, self-compassion, self-efficacy, and gender as predictors of depression, anxiety, stress, and well-being. Mindfulness, 6, 217-226. https://doi.org/10.1007/ s12671-013-0247-1.

Sprang, G., Clark, J. J., \& Whitt-Woosley, A. (2007). Compassion fatigue, compassion satisfaction, and burnout: factors impacting a professional's quality of life. Journal of Loss and Trauma, 12, 259-280. https://doi.org/10.1080/15325020701238093.

Stafford-Brown, J., \& Pakenham, K. I. (2012). The effectiveness of an $\mathrm{ACT}$ informed intervention for managing stress and improving therapist qualities in clinical psychology trainees. Journal of Clinical Psychology, 68, 592-513. https://doi.org/10.1002/jclp.21844.

Stern, G. S., McCants, T. R., \& Pettine, P. W. (1982). Stress and illness: controllable and uncontrollable life events' relative contributions. Personality and Social Psychology Bulletin, 8, 140-145. https:// doi.org/10.1177/014616728281022

Stoeber, J., Otto, K., \& Dalbert, C. (2009). Perfectionism and the big five: conscientiousness predicts longitudinal increases in self-oriented perfectionism. Personality and Individual Differences, 47, 363368. https://doi.org/10.1016/j.paid.2009.04.004.

Su, J., Weng, H., Tsang, H., \& Wu, J. (2009). Mental health and quality of life among doctors, nurses and other hospital staff. Stress and Health, 25, 423-430. https://doi.org/10.1002/smi.1261.

Sutherland, L. M., Kowalski, K. C., Ferguson, L. J., Sabiston, C. M., Sedgwick, W. A., \& Crocker, P. R. E. (2014). Narratives of young women athletes' experiences of emotional pain and self-compassion. Qualitative Research in Sport, Exercise and Health, 6, 499516. https://doi.org/10.1080/2159676X.2014.888587.

Van Dam, N. T., Sheppard, S. C., Forsyth, J. P., \& Earleywine, M. (2010). Self-compassion is a better predictor than mindfulness of symptom severity and quality of life in mixed anxiety and depression. Journal of Anxiety Disorders, 25, 123-130. https://doi.org/10.1016/j. janxdis.2010.08.011.

Van Den Tooren, M., \& De Jonge, J. (2008). Managing job stress in nursing: what kind of resources do we need? Journal of Advanced Nursing, 63, 75-84. https://doi.org/10.1111/j.1365-2648.2008. 04657.x. 
Vigna, A. J., Poehlmann-Tynan, J., \& Koenig, B. W. (2017). Does selfcompassion facilitate resilience to stigma? A school-based study of sexual and gender minority youth. Mindfulness, 9, 1-11. https://doi. org/10.1007/s12671-017-0831-x.

Visser, M. R. M., Smets, E. M. A., Oort, F. J., \& de Haes, H. C. (2003). Stress, satisfaction and burnout among Dutch medical specialists. Canadian Medical Association Journal, 168, 271-275.

Wear, D., \& Zarconi, J. (2008). Can compassion be taught? Let's ask our students. Journal of General Internal Medicine, 23, 948-953. https://doi.org/10.1007/s11606-007-0501-0.

Weinberg, A., \& Creed, F. (2000). Stress and psychiatric disorder in healthcare professionals and hospital staff. The Lancet, 355, 533537. https://doi.org/10.1016/S0140-6736(99)07366-3.
Wenzel, L. B., Fairclough, D. L., Brady, M. J., Cella, D., Garrett, K. M., Kluhsman, B. C., et al. (1999). Age-related differences in the quality of life of breast carcinoma patients after treatment. Cancer, 86, 1768. https://doi.org/10.1002/(SICI)1097-0142(19991101).

White, P. (2000). Doctors and nurses. Let's celebrate the difference between doctors and nurses. BMJ, 321, 698.

Zessin, U., Dickhäuser, O., \& Garbade, S. (2015). The relationship between self-compassion and well-being: a meta-analysis. Applied Psychology: Health and Well-Being, 7, 340-364. https://doi.org/ 10.1111/aphw.12051.

Publisher's Note Springer Nature remains neutral with regard to jurisdictional claims in published maps and institutional affiliations. 